\title{
Mariano Álvarez Gómez (1935-2017)
}

Mariano Álvarez-Gómez (1935-2017) se licenció en Filosofía y en Teología por la Universidad Pontificia de Salamanca y prosiguió sus estudios en la Universidad de Munich, donde se doctoró "cum laude" con una tesis sobre el tema de la infinitud en Nicolás de Cusa. El prestigio internacional que alcanzó su trabajo, Die verborgene Gegenwart des Unendlichen bei Nikolaus von Kues (Pustet, München, 1968) le situó entre los investigadores más destacados sobre Cusa y el contexto filosófico de su época. Durante su larga estancia en Alemania, su interés por el problema de la infinitud le llevó en seguida a Hegel, al que ha dedicado numerosos e importantes estudios a lo largo de su carrera académica. En 1976 se doctoró en Filosofía por la Universidad de Valencia, con su tesis: Experiencia y Sistema. Introducción al pensamiento de Hegel (Salamanca, 1978), un trabajo innovador que impulsó los estudios sobre Hegel en España. En 1982, obtuvo la Cátedra de Historia de la Filosofía Antigua y Medieval y en 1983 la Cátedra de Metafísica, ambas en la Universidad de Salamanca, que le nombró Profesor Emérito Honorífico. Fue miembro-fundador de la Sociedad Española de Filosofía Medieval y durante décadas ha pertenecido al Comité Científico de la Cusanus-Gesellschaft. Como Presidente-Fundador de la Sociedad Española de Estudios sobre Hegel (1996-2010) y Presidente de la Sociedad Castellano-Leonesa de Filosofia (1985-2001) ha impulsado encuentros filosóficos muy fructíferos entre filósofos y estudiosos tanto a nivel nacional como internacional. En 2005 fue elegido Miembro de número de la Real Academia Española de Ciencias Morales y Políticas.

La vida y obra de Mariano Álvarez se caracteriza por su gran aportación intelectual a la filosofía, así como por la grandeza de su magisterio, desde sus comienzos en las Universidades de Munich y Bonn hasta su dilatada carrera docente en las Universidades de Salamanca. Sobre su extenso legado, nos referiremos aquí únicamente al pensamiento medieval y su contexto más próximo.

En primer lugar, destacamos la dimension metafísica del pensamiento de Mariano Álvarez, vertebrada por su interés en el problema de la verdad, como él mismo escribe en su prólogo al citado libro sobre el Cusano. Esta reivindicación de la metafísica articula trabajos dedicados a Aristóteles, San Agustín, Tomás de Aquino, San Anselmo y Duns Scoto. Mariano Álvarez sostiene el "carácter antitético de la metafísica", y la vertebración de esta antítesis en sus aspectos lógico y ontológico. Ejemplo de ello es el principio de contradicción, cuyo significado desde Aristóteles es en realidad el de un "principio de no-contradicción" que a través de la filosofía antigua y medieval se proyecta con diferentes modulaciones hasta nuestros días. También es preciso mencionar el importante estudio sobre el Sentido de la validez del argumento “ontológico” de San Anselmo (Proslogion, Madrid, 2009), en el que se profundiza sobre el alcance de este argumento para diferentes marcos conceptuales de toda filosofía fundamental. Otros principios metafísicos son objeto de investigaciones sobre Tomás de Aquino y Duns Scoto, así como el tema de la razón en la historia en San Agustín. Característica de todos estos trabajos es la decidida actualización de dichos autores en relación con los problemas de la filosofía. 
Ciertamente, donde se aprecia más explícitamente la potencia y originalidad intelectual de Mariano Álvarez es en su investigación sobre Nicolás de Cusa. En cada uno de sus numerosos trabajos, Mariano Álvarez pone de manifiesto los elementos más innovadores del Cusano, tanto en el ámbito del conocimiento, como en el de la metafísica y en el de la religión. La cuestión sobre cómo la infinitud de Dios tiene que ser pensada desde dentro y hacerse visible en las más variadas configuraciones de lo finito es un elemento fundamental en muchos de estos estudios. Así la presenta en "Peculiaridad de la pregunta sobre Dios"1, cuyo planteamiento fue decisivo para la investigación sobre N. de Cusa. Mariano Álvarez sitúa en el límite al pensamiento filosófico del Cusano desde múltiples horizontes, en los que saca a la luz su densidad ontológica. Uno de esos horizontes es el que tiene que ver con la religión. Los estudios de Mariano Álvarez sobre conceptos religiosos de N. de Cusa abarcan también aspectos que actualmente se valoran de modo especial, como son el consenso y el diálogo interreligioso, la búsqueda de la paz y la concordia en la fe. Muchos de estos escritos están publicados en alemán por la Cusanus-Gesellschaft. Recientemente, se ha publicado en español la excelente edición bilingüe de La caza de la sabiduría (Salamanca, 2014), donde Mariano Álvarez incluye, además de su traducción, una introducción, un comentario filosófico y abundante información crítica y bibliográfica.

Una tercera línea de investigación en filosofía medieval tiene por objeto a la mística. Mariano Álvarez ha dedicado al Maestro Eckhart varios estudios, de los cuales se han publicado dos: "Unidad y reflexión" (1996) y "El Maestro Eckhart y su huella" (2017). El primero aborda el problema de los trascendentales como sustantivación de cualidades que expresan la prioridad de lo ideal sobre lo real y que remiten al ser como fundamento último de su comprensibilidad. En esta línea se establece la reflexión sobre la nada, la negación y el no-ser en cuanto conceptualizaciones que tienen su anclaje en la unidad y en la verdad, como principios de inteligibilidad del pensamiento del místico medieval. "El Maestro Eckhart y su huella" es el último trabajo publicado por Mariano Álvarez (Filosofía, arte y mística (Salamanca, 2017, 105-118)). En él se nos invita a adentrarnos en el lenguaje del místico para desentrañar la presencia activa del misterio y para lograr un esclarecimiento de significado que, lejos de llevarnos a conclusiones determinadas, nos sitúa siempre en un nuevo comienzo. Mariano Álvarez nos permite dirigir la atención hacia el poder y los límites del lenguaje en Eckhart y encontrar en Erich Fromm, Kurt Flasch o Heidegger una nueva mirada hacia este autor.

Mariano Álvarez-Gómez falleció en Salamanca, el 13 de Octubre de 2017.

\section{MARÍA DEL CARMEN PAREDES MARTÍN}

Universidad de Salamanca

1 Incluido en Pensamiento del ser y espera de Dios, Sígueme, Salamanca, 2004, 43-65. 